Biosystems Engineering (2006) 93(4), 415-425

doi:10.1016/j.biosystemseng.2006.01.001

SE-Structures and Environment
Available online at www.sciencedirect.com

Science@Dinect.

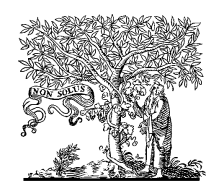

ELSEVIER

\title{
Similitude Criteria for a Two-dimensional Wall Jet in an Isothermal Mechanically Ventilated Enclosure
}

\author{
Hsin $\mathrm{Yu}^{1, *}$; Li-John $\mathrm{Jou}^{2}$; Huei-Tau Ouyang ${ }^{1}$; Huang-Min Liang ${ }^{3}$; Chung-Min Liao ${ }^{3}$ \\ ${ }^{1}$ Department of Civil Engineering, National Ilan University, Ilan 26041, Taiwan, ROC; \\ e-mail of corresponding author: yuhsin@niu.edu.tw \\ ${ }^{2}$ Department of Biomechatronic Engineering, National Ilan University, Ilan 26041, Taiwan, ROC \\ ${ }^{3}$ Department of Bioenvironmental Systems Engineering, National Taiwan University, Taipei 10617, Taiwan, ROC
}

(Received 15 April 2005; accepted in revised form 5 January 2006; published online 7 March 2006)

\begin{abstract}
A scale model experiment is an important method to study ventilation airflow pattern inside buildings that affects indoor air quality. The similitude criteria are the decision factors to guarantee using the result of model study to predict actual airflow of prototype. It is important to decide the similitude criteria between scale model and prototype. The aim of this project focuses on deciding the similitude criteria of a two-dimensional wall jet between the model and prototype to establish same airflow pattern in an isothermal mechanically ventilated enclosure. The parameters of the Reynolds number, Euler number, and jet momentum ratio proposed by previous researchers are investigated to find which parameter is the similitude criterion for a twodimensional wall jet in isothermal condition. Experiments were conducted in two geometrically similar scale models. The similitude criteria were verified by comparing latent parameters with airspeed distribution following the kinematic similitude, whereas the airflow pattern following the dynamic similitude between the model and prototype. Experimental results indicate that the Euler number is not the similitude criterion, but the jet momentum ratio related to inlet airspeed is the similitude criterion of a two-dimensional wall jet in an isothermal mechanically ventilated enclosure. Reynolds number may be used as the similitude criterion only for flows at low Reynolds numbers. Our results are useful for the researcher to decide the parameters and boundary conditions of scale model study for the prediction of prototype performance of a two-dimensional wall jet in an isothermal mechanically ventilated enclosure.
\end{abstract}

(C) 2006 Silsoe Research Institute. All rights reserved

Published by Elsevier Ltd

\section{Introduction}

Ventilation is an important technique to regulate the room environment and produce an appropriate microclimate for the occupant's thermal comfort and indoor air quality. The behaviour of ventilated airflow inside an enclosure influences the air distribution, thermal environment, and contaminant concentration. In most mechanically ventilated rooms, air-jets are used to mix inlet air with room air. The air-jet performance determines the distribution of thermal energy, moisture, and fresh air in a room (Awbi, 1991).

The characteristics of an enclosed air-jet have been studied by using prototype buildings, scale-models, and numerical simulation. However, a precise mathematical model is impossible for the extremely complex microstructure of room airflow (Moog, 1981). Model tests will always be required if the prototype building is not available and no precisely mathematical-physical prediction model is established. Model studies are practical for simulating the behaviour of a prototype and can be used to validate a numerical simulation. Similitude, or the relation between a model and prototype, is an important issue when using model studies (Yu, 1996).

The similitude criterion between a model and prototype is important to guarantee that the experimental results of the model can be used to predict the behaviour of the prototype building. Complete similitude of the isothermal airflow field between the model and prototype must satisfy the geometric similitude, kinematic 


\begin{tabular}{|c|c|c|c|}
\hline \multicolumn{4}{|c|}{ Notation } \\
\hline$a$ & air-jet acceleration, $\mathrm{m} / \mathrm{s}^{2}$ & & air-jet velocity along the $\mathrm{Y}$ axis, $\mathrm{m} / \mathrm{s}$ \\
\hline & throw constant & & terminal velocity of the air-jet, $\mathrm{m} / \mathrm{s}$ \\
\hline & slot outlet height, $\mathrm{m}$ & & air-jet velocity at diffuser, $\mathrm{m} / \mathrm{s}$ \\
\hline$E u$ & Euler number & $u_{m a-}$ & maximum velocity of the air-jet at specific \\
\hline$H$ & enclosure height, $\mathrm{m}$ & $x$ & distance from the inlet wall, $\mathrm{m} / \mathrm{s}$ \\
\hline$h$ & slot inlet height, $\mathrm{m}$ & $W$ & enclosure width, $\mathrm{m}$ \\
\hline$J$ & jet momentum number & $w$ & slot inlet width, m \\
\hline$L$ & enclosure length, m & $x$ & horizontal distance from the inlet wall, $\mathrm{m}$ \\
\hline$L_{j}$ & jet throw, m & & distance along the $\mathrm{X}$ axis, $\mathrm{m}$ \\
\hline$L^{\prime}$ & length of exhaust plenum of the test cham- & & distance along the $\mathrm{Y}$ axis, $\mathrm{m}$ \\
\hline$P$ & $\begin{array}{l}\text { ber, } \mathrm{m} \\
\text { pressure, } \mathrm{N} / \mathrm{m}^{2}\end{array}$ & $\begin{array}{l}y \\
\Delta P\end{array}$ & $\begin{array}{l}\text { vertical distance from floor, } \mathrm{m} \\
\text { pressure difference, } \mathrm{N} / \mathrm{m}^{2}\end{array}$ \\
\hline$Q$ & airflow rate, $\mathrm{m}^{3} / \mathrm{s}$ & & density of air, $\mathrm{kg} / \mathrm{m}^{3}$ \\
\hline$R^{2}$ & coefficient of determination & & \\
\hline $\operatorname{Re}$ & Reynolds number & \multicolumn{2}{|c|}{ Subscripts } \\
\hline$R_{m}$ & inlet jet momentum ratio, $\mathrm{m}^{2} / \mathrm{s}^{2}$ & & diffuser \\
\hline$t$ & time, $\mathrm{s}$ & $m$ & model \\
\hline$u$ & air-jet velocity, $\mathrm{m} / \mathrm{s}$ & $p$ & prototype \\
\hline$u_{i}$ & air-jet velocity along the $\mathrm{X}$ axis, $\mathrm{m} / \mathrm{s}$ & & \\
\hline
\end{tabular}

similitude, dynamic similitude, and all boundary conditions (Shepherd, 1965; Baturin, 1972; Szucs, 1980; Awbi, 1991; Zhang et al., 1991). Only partial similarity between the model and prototype could be satisfied because most of the dimensionless parameters affecting airflow performance have equal importance in most of the realistic problems.

Reynolds number $R e$ has been widely used as the similitude criterion for an isothermal airflow in an enclosure (Pattie \& Milne, 1966; Smith \& Hazen, 1968; Albright, 1976; Timmons \& Baughman, 1981; Timmons, 1984; Yao et al., 1986; Jin \& Ogilvie, 1992), but experimental results do not always show that the Reynolds number is the appropriate similitude criterion (Zhang et al., 1991; Adre \& Albright, 1994; Yu \& Hoff, 1994, 1999).

Jet momentum ratio $R_{m}$, which is defined as the ratio of inertia force (inlet jet momentum) and total drag (momentum loss) due to viscous shear at the walls of the enclosure (Adre \& Albright, 1992), has been validated as an appropriate similitude criterion through recent experiments (Adre \& Albright, 1994; Yu \& Hoff, 1994, 1999), but $R_{m}$ in $\mathrm{m}^{2} / \mathrm{s}^{2}$ is a dimensional parameter and is not a valid criterion since a similitude parameter must be dimensionless (Murphy, 1950; Szucs, 1980). Jet momentum number $J$ was proposed by Barber et al. (1982) and has been verified as an improper similitude criterion between the model and prototype by experimental validation (Timmons, 1984; Adre \& Albright, 1994).
Liu et al. (1995) compared three ventilation criteria (Reynolds number, jet momentum number, and jet momentum ratio) analytically under isothermal conditions. Reynolds number was found to be the correct similitude criterion based on a dimensional analysis and the Navier-Stokes equations. They concluded that previous research which showed the inappropriateness of Reynolds number as the similitude criterion might be the results of experimental errors, such as the failure of similarity in turbulent boundary conditions between the model and prototype. Using $R_{m}$ as the similitude criterion will result in the same inlet airspeed $u_{d}$ in $\mathrm{m} / \mathrm{s}$ in both the model and prototype. The same values of $u_{d}$ for the model and prototype leading to the conclusion that a turbulent flow in the prototype will be similar to a laminar flow in the model was questioned.

Rousseau and Albright (1996) stated an anomaly in the use of Reynolds number as the kinematic similitude criterion for scale modelling of slot-ventilated enclosures. Reynolds number has a negligible effect on the governing equations of fluid dynamics when compared to that of Euler number $E u$ which becomes an alternative kinematic similitude criterion instead of $R e$.

The conclusion of similarity analysis indicates that the possible similarity parameters for the isothermal airflow in an enclosure are geometry, Froude number, Euler number, jet momentum ratio, and Reynolds number between the model and the prototype (Yu, 1996). The Froude number is important for compressible flow and 
for motion with free liquid-vapour surfaces in the flow (Schlichting, 1979). The isothermal airflow in a confined space is considered as a homogeneous fluid without free liquid-vapour surfaces, thus the Froude number could be neglected (Zhang, 1991). The remaining similarity parameters require higher inlet airspeed in the model based on $R e$ but the same inlet airspeed between the model and prototype based on both $E u$ and $R_{m}$.

The objective of this study is to investigate similitude criteria of a two-dimensional wall jet airflow between a scale-model and a prototype confined enclosure for isothermal conditions. The sub-objectives are to validate the Reynolds number, jet momentum ratio, and Euler number that proposed by previous researches as the similitude criteria for isothermal condition. The ultimate purpose of this research is to develop guidelines when using scale-models for assessing prototype behaviour of a two-dimensional wall jet airflow patterns in confined spaces. The desire is to predict airflow patterns and airspeed distribution, especially within the animal occupied zone in the prototype building.

\section{Methods and materials}

Two geometrically similar scale models representing a scale-model and a prototype with ratio of 1:2 were used to study airflow similitude criteria. The ratio of geometry between the scale-model and prototype is defined from the previous literatures (Smith \& Hazen, 1968; Adre \& Albright, 1994; Yu \& Hoff, 1994). The airflow patterns and variation in velocity fields were measured by airspeed measurements. The test chambers used are shown in Fig. 1. The slot inlet width $w$ in $\mathrm{m}$ was the same as the width of the enclosure $W$ in $\mathrm{m}$. The inlet aspect ratio was much larger than 20, and as a result, the airflow was treated as a two-dimensional wall jet without the effect of side walls (Forthmann, 1934).

The scale models were made from $12.7 \mathrm{~mm}$ thick plywood. The inner surfaces of the models were sanded and painted black. The front wall was made of Plexiglas to accommodate airflow visualisation. A portion of the top ceiling was fabricated with Plexiglas, which extended along the length of both models for illuminating purposes. Both models had an exhaust plenum between the test room and exhaust duct to reduce the effect of exhaust airflow from the slot outlet. Exhaust fan with circular duct was provided on the outlet wall. A $150 \mathrm{~mm}$ diameter duct was used for both models. Calibrated orifice plates were used within duct to select desired airflow rates through each model. A micro-manometer transducer was used to measure the pressure difference across the orifice to determine airflow rate.

Airspeed was measured with hot-film anemometers (model 8455 and 8475; TSI, Inc., USA) which were mounted on an traverse system automatically controlled

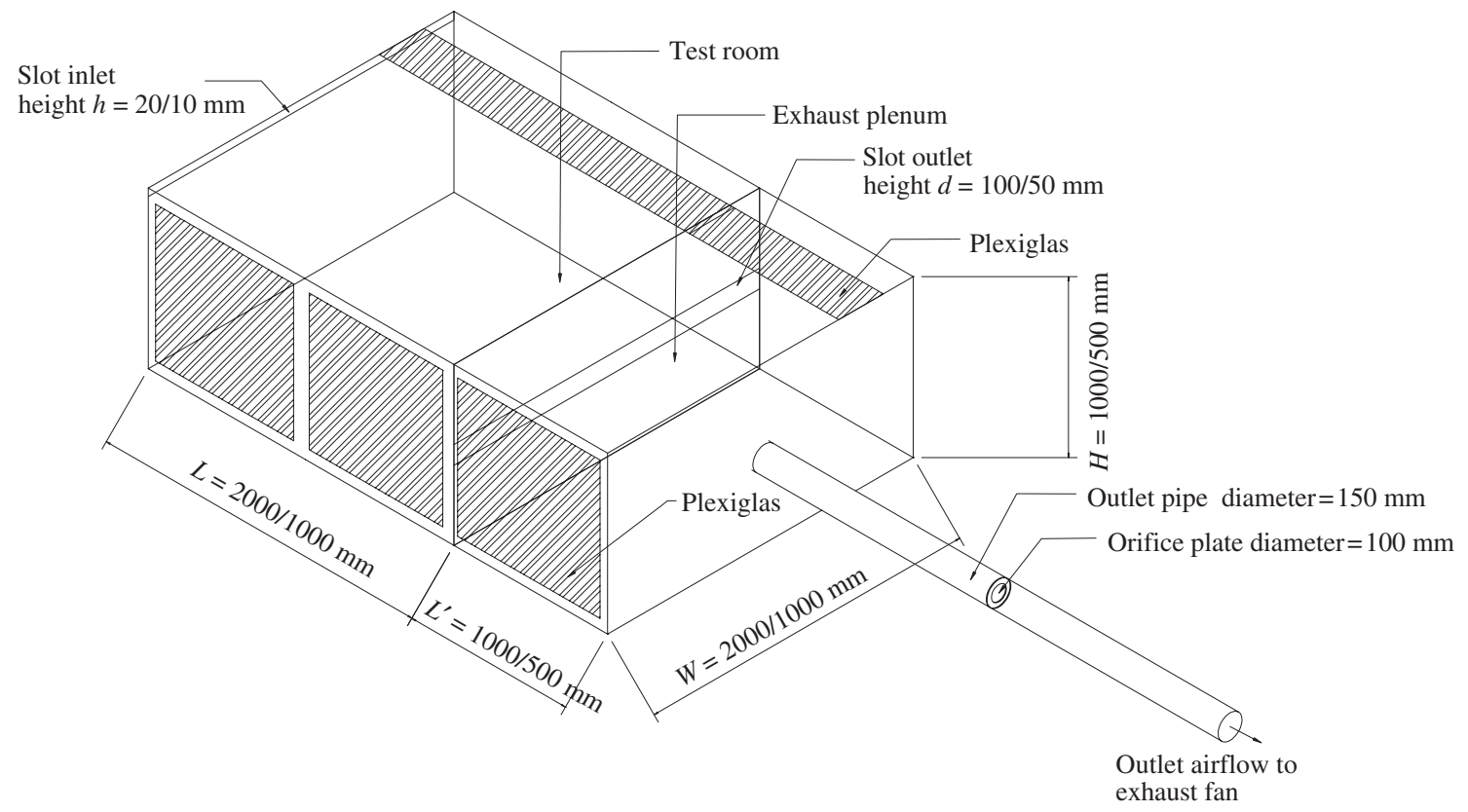

Fig. 1. The scheme and dimensions (prototype/model) of test chambers used in this study: H, enclosure height; L, enclosure length; $W$, enclosure width; L' length of exhaust plenum of the test chamber 
with a programmable logic controller. A portable data acquisition system (model CR10; Campbell Scientific Inc., USA) was used to collect data. The sampling frequency was set at $16 \mathrm{~Hz}$. The sampling period was fixed at $180 \mathrm{~s}$ per collection point to ensure accurate time-averaged results for turbulent airflow (Thorshauge, 1982). This sampling period was much longer than was used in previous similar studies (Zhang, 1991; Adre \& Albright, 1994). The average value over time, at a point, was used for analysis and presentation. The wall jet peak velocity was measured at values for $x$ of $0.25 \mathrm{~L}, 0.5 \mathrm{~L}$, and $0.75 \mathrm{~L}$ in both the model and prototype, where $x$ is the specific distance in $\mathrm{m}$ from inlet wall and $L$ is the length of the enclosure in $\mathrm{m}$. Each peak velocity was determined from the vertical jet velocity profile at specific distance from the inlet wall.

\section{Results and discussion}

The ranges of airflow rates with corresponding values of $R e, R_{m}, E u$ and $u_{d}$ used to investigate airflow performances in an enclosure are shown in Table 1. Typical vertical velocity profiles of a plane wall jet at values for $x$ of $0.25 \mathrm{~L}, 0.5 \mathrm{~L}$, and $0.75 \mathrm{~L}$ with inlet airspeed of 3.41 and $3.56 \mathrm{~m} / \mathrm{s}$ for the model and prototype respectively are shown in Fig. 2. The peak velocity of the two-dimensional wall jet at a specific distance is determined from the above vertical velocity profile. The peak velocity of the air-jet decreases with the increased distance from the inlet wall because of the raised entrainment compensates the initial momentum of the air-jet from the inlet.

The normalised wall jet peak velocities related to the normalised distances from the inlet wall are shown in

Table 1

Test conditions of airflow rates without corresponding values of parameters for isothermal airflow

\begin{tabular}{llccccc}
\hline Test & & $\begin{array}{c}\text { Airflow rate }(Q), \\
\mathrm{m}^{3} / \mathrm{s}\end{array}$ & $\begin{array}{c}\text { Air-jet velocity at } \\
\text { diffuser }\left(u_{d}\right), \mathrm{m} / \mathrm{s}\end{array}$ & $\begin{array}{c}\text { Reynolds number } \\
(\text { Re })\end{array}$ & $\begin{array}{c}\text { Inlet jet } \\
\text { momentum ratio } \\
\left(R_{m}\right)\end{array}$ & $\begin{array}{c}\text { Euler number } \\
(\text { Eu })\end{array}$ \\
\hline Prototype & Minimum & 0.0403 & 1.01 & 1347 & 0.01 & 0.427 \\
Model & Maximum & 0.1420 & 3.55 & 4746 & 0.08 & 0.323 \\
& Minimum & 0.0175 & 1.75 & 1170 & 0.02 & $0 \cdot 047$ \\
\hline
\end{tabular}

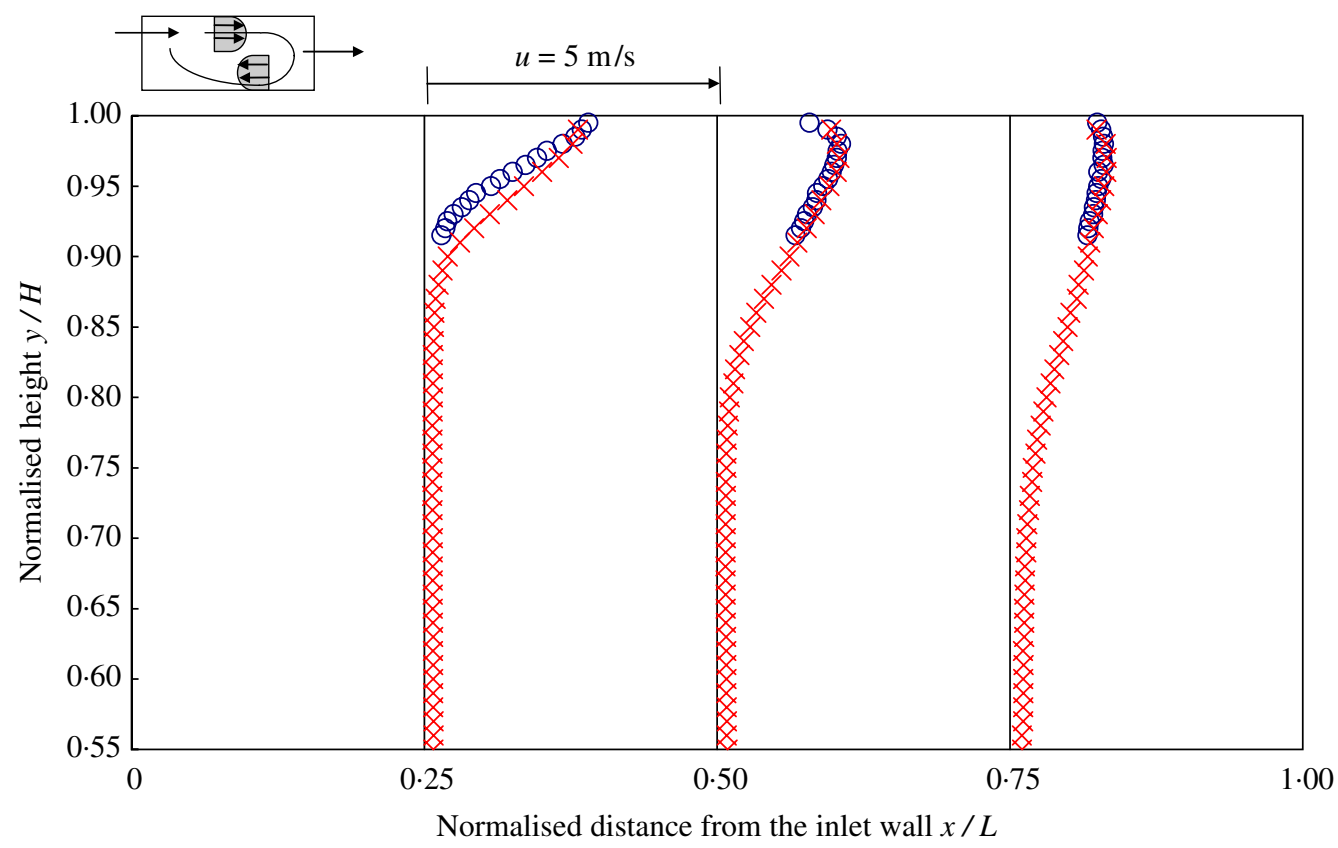

Fig. 2. The vertical velocity profile of a plane wall jet at distance $x$ of $0 \cdot 25 \mathrm{~L}, 0.5 \mathrm{~L}$, and $0 \cdot 75 \mathrm{~L}$ from the inlet wall at specific inlet airspeed as 3.41 and $3.56 \mathrm{~m} / \mathrm{s}$ of the model and prototype respectively: 0 , prototype; $\times$, model; $x$, horizontal distance from the inlet wall; $y$, vertical distance from floor; L, enclosure length; $H$, enclosure height; $u$, air-jet velocity 


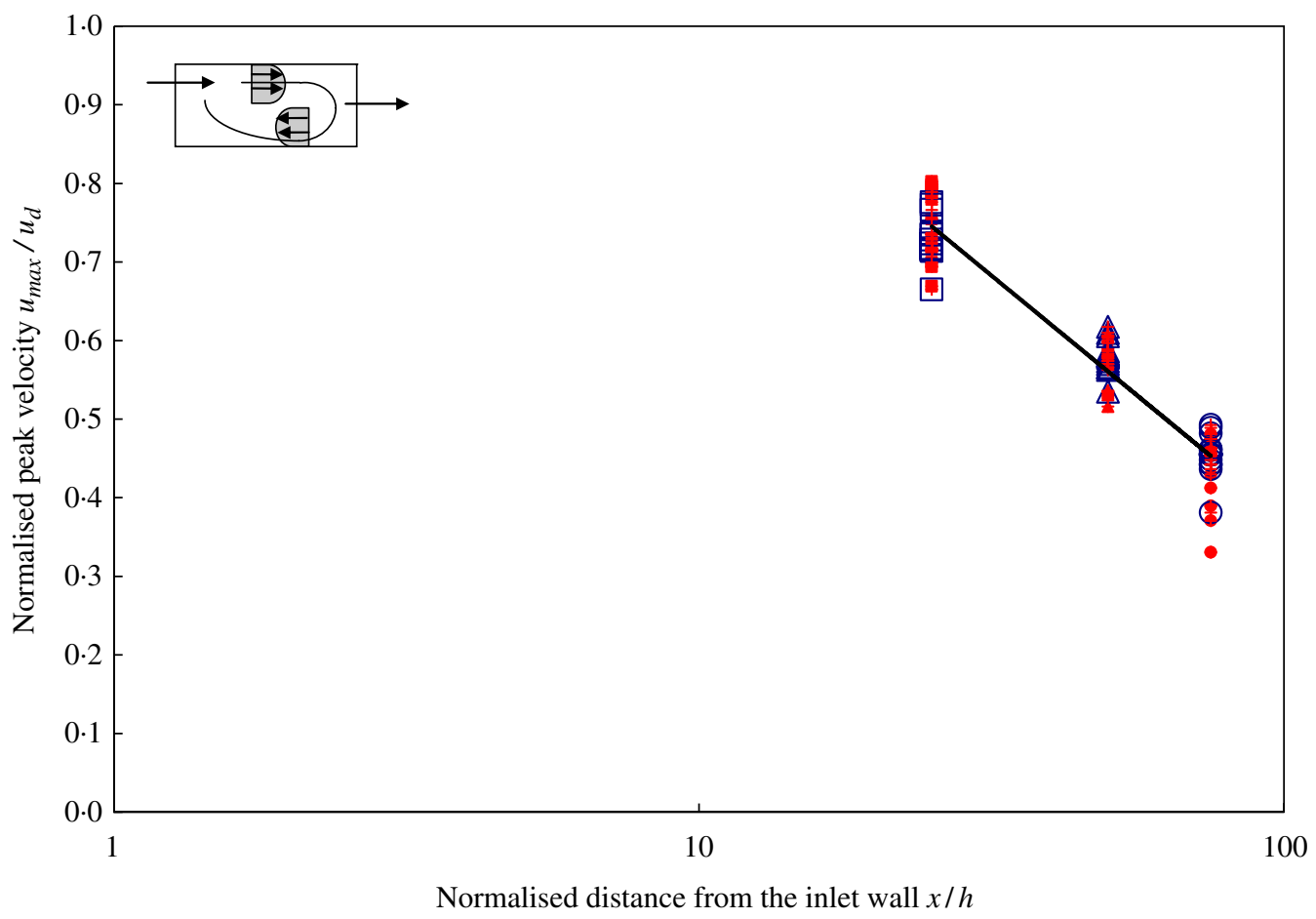

Fig. 3. Normalised peak velocity at different normalised specific distance from the inlet wall: $\mathbf{\square}$, at $0 \cdot 25 \mathrm{~L}$ of prototype; $\mathbf{\Delta}$, at $0 \cdot 5 \mathrm{~L}$ of prototype; $\bullet$, at $0.75 \mathrm{~L}$ of prototype; $\square$, at $0.25 \mathrm{~L}$ of model; $\triangle$, at $0.5 \mathrm{~L}$ of model; 0 , at $0.75 \mathrm{~L}$ of model; - , regression line; $u_{\text {max }}$, the maximum velocity of air-jet at specific distance from inlet wall; $u_{d}$, the air-jet velocity at diffuser; $x$, specific distance from the inlet wall; $h$, height of the slot inlet

Fig. 3. All the specific distances of $0.25 \mathrm{~L}, 0.5 \mathrm{~L}$, and $0.75 \mathrm{~L}$ are within the range of values for $x$ between $10 \mathrm{~h}$ to $100 h$ which belongs to the characteristic decay region of a plane wall jet (Awbi, 1991). The normalised peak velocity of a plane wall jet in the characteristic decay region is proportional to the square root of the ratio between the slot height $h$ in $\mathrm{m}$ and the stream-wise distance of the air-jet from the inlet wall $x$ as (Awbi, 1991; Yu \& Hoff, 1999):

$$
\frac{u_{\max }}{u_{d}}=C_{w} \sqrt{\frac{h}{x}}
$$

where: $u_{\max }$ is the maximum velocity of the air-jet at specific distance from the inlet wall in $\mathrm{m} / \mathrm{s} ; u_{d}$ is the airjet velocity at diffuser in $\mathrm{m} / \mathrm{s}$; and $C_{w}$ is the throw constant.

The throw constant in the model and the prototype are estimated as 3.89 and 3.84 respectively, and the average value is 3.87 . The similar value of throw constant between the model and prototype indicates that the normalised peak velocity of a plane wall jet at comparable distance from the inlet wall is analogous between the model and prototype.

The normalised peak velocities of the air-jet at distances of $0.25 \mathrm{~L}, 0.5 \mathrm{~L}$, and $0.75 \mathrm{~L}$ from the inlet wall versus Re, $R_{m}, E u$, and $u_{d}$ are shown in Fig. 4. The plots of the normalised wall jet peak velocity at specific distance from the inlet wall related to the different parameters are invariable because the self-similarity of the peak velocity. If the normalised travel distance of the air-jet from the inlet wall $x / h$ is defined, the normalised peak velocity of the air-jet only depends on the throw constant according to Eqn (1) and is independent on the parameters of $R e, R_{m}, E u$, and $u_{d}$.

The plots of peak velocities at specific distances from the inlet wall varied as a function of $R e, R_{m}, E u$, and $u_{d}$ are shown in Fig. 5. The plots of peak velocities against $\mathrm{Re}$ and Eu [Fig. 5(a) and (c)] fall in different curves between the model and prototype. Only the plots against $R_{m}$ and $u_{d}$ [Fig. 5(b) and (d)] fall in the same curve with data from different models. The equations of regression lines in both models with $R e, R_{m}$ and $u_{d}$ at values for $x$ of $0.25 \mathrm{~L}, 0.5 \mathrm{~L}$, and $0.75 \mathrm{~L}$ are shown in Table 2. All regression lines indicate appropriate correlation with coefficient of determination $R^{2}$ greater than $0 \cdot 97$. The plot of peak velocities of the air-jet with $E u$ shows irregular curves in both the model and prototype.

The peak velocities of the air-jet at comparable positions are similar in both the model and prototype only when same $u_{d}$ or $R_{m}$ is employed. It is shown that the same $u_{d}$ or $R_{m}$ will result in the same peak 

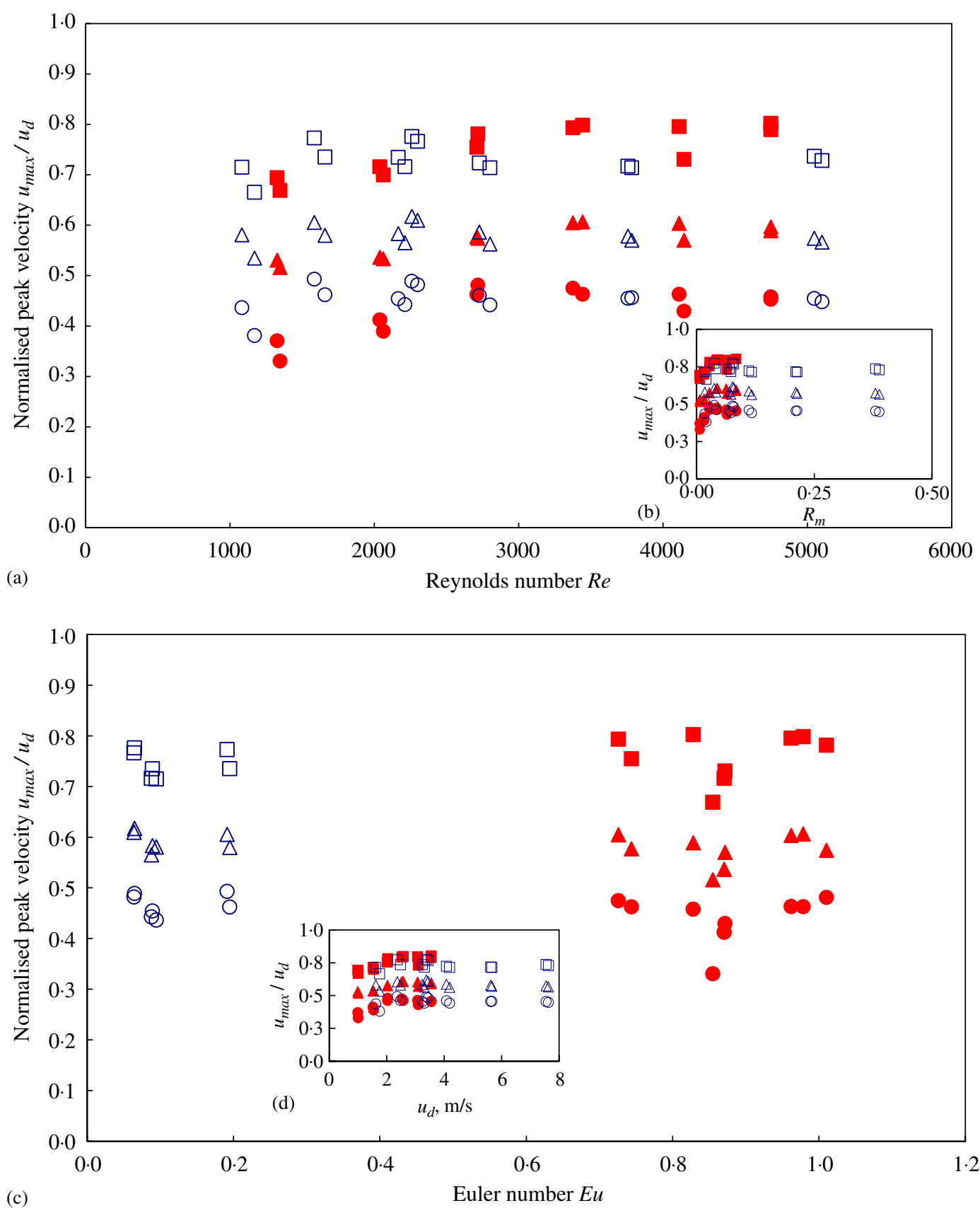

Fig. 4. The normalised peak velocity of a plane wall jet related without (a)Reynolds number Re; (b) jet momentum ratio $R_{m}$; (c) Euler number $\mathrm{Eu}$; and $(d)$ air-jet velocity at diffuser $u_{d}$ at distance of $0 \cdot 25 \mathrm{~L}, 0 \cdot 5 \mathrm{~L}, 0 \cdot 75 \mathrm{~L}$ from the inlet wall: $\mathbf{0}$, at $0 \cdot 25 \mathrm{~L}$ of prototype; $\Delta$, at $0.5 \mathrm{~L}$ of prototype; $\bullet$, at $0.75 \mathrm{~L}$ of prototype; $\square$, at $0.25 \mathrm{~L}$ of model; $\triangle$, at $0.5 \mathrm{~L}$ of model; 0 , at $0.75 \mathrm{~L} \mathrm{of} \mathrm{model;} \mathrm{L}$, enclosure length; $u_{\text {max }}$, maximum velocity of the air-jet at specific distance from the inlet wall

velocities of a plane wall jet at comparable positions between the model and prototype. The normalised, Reynolds-averaged Navier-Stokes equation of momentum balance for an elemental portion of fluid at position $x$ and time $t$ in $\mathrm{s}$ is

$$
\frac{\partial u_{i}}{\partial t}+u_{j} \frac{\partial u_{j}}{\partial x_{j}}+\frac{\partial u_{i} u_{j}}{\partial x_{j}}=-\frac{E u}{2} \frac{\partial P}{\partial x_{i}}+\frac{1}{R e} \frac{\partial^{2} u_{i}}{\partial x_{i} \partial x_{j}}
$$

where: $u_{i}, u_{j}$ are the air-jet velocities in the $\mathrm{X}$ direction and $\mathrm{Y}$ direction, respectively, in $\mathrm{m} / \mathrm{s} ; x_{i}, x_{j}$ are distances in the $\mathrm{X}$ direction and $\mathrm{Y}$ direction, respectively, in $\mathrm{m}$; and $P$ is pressure in $\mathrm{N} / \mathrm{m}^{2}$.

By using the method of order of magnitude, it confirms that above a certain threshold value $1 / R e$ becomes infinite and the $R e$ can be neglected comparing to that of Eu (Rousseau \& Albright, 1996). However, 

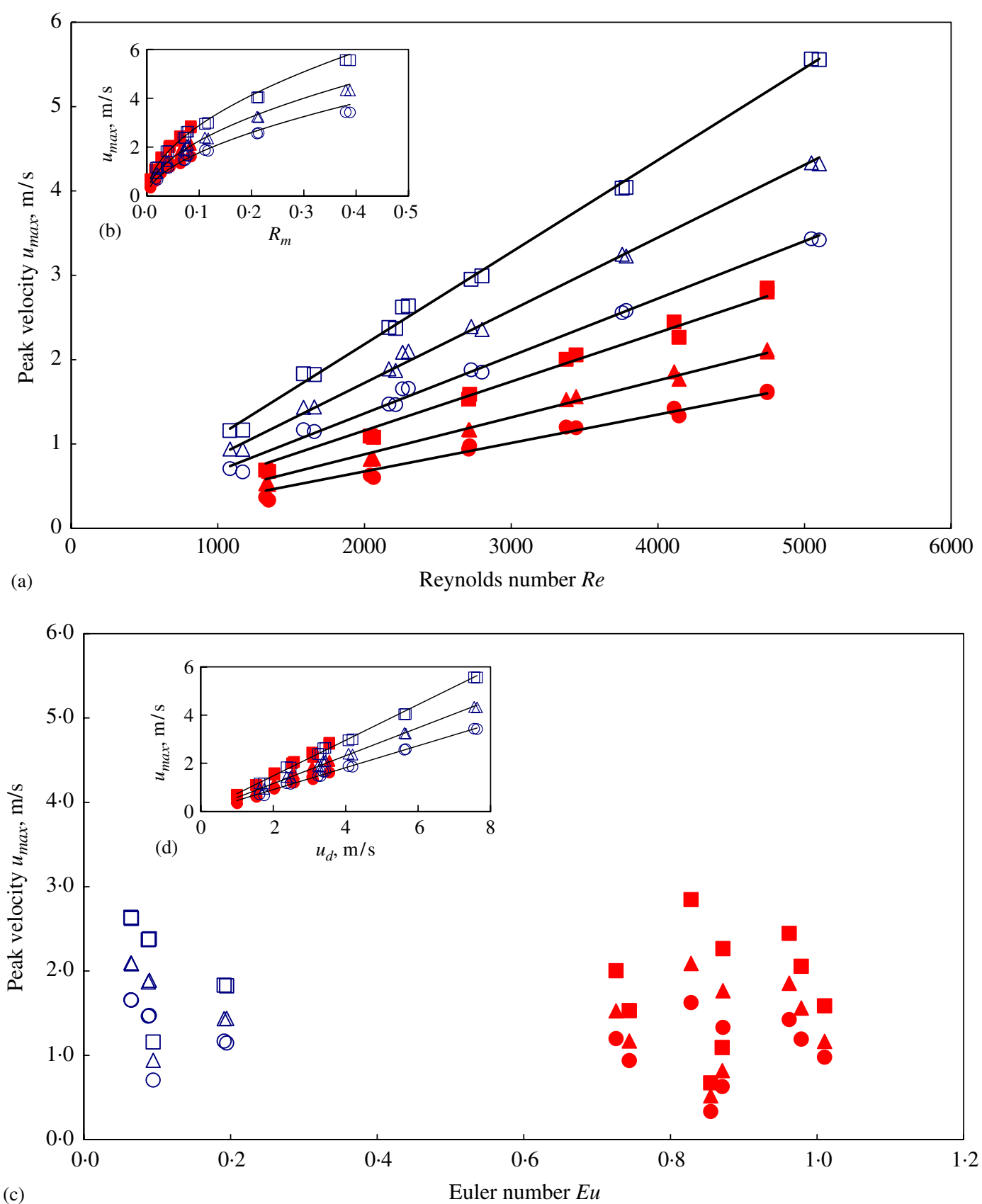

Fig. 5. The peak velocity of a plane wall jet related without (a) Reynolds number Re; (b) jet momentum ratio $R_{m}$; (c) Euler number $\mathrm{Eu}$; and $(d)$ air-jet velocity at diffuser $u_{d}$ at distance of $0.25 \mathrm{~L}, 0.5 \mathrm{~L}, 0.75 \mathrm{~L}$ from the inlet wall: $\square$, at $0.25 \mathrm{~L}$ of prototype; $\Delta$, at $0.5 \mathrm{~L}$ of prototype; $\bullet$, at $0.75 \mathrm{~L}$ of prototype; $\square$, at $0.25 \mathrm{~L}$ of model; $\triangle$, at $0.5 \mathrm{~L}$ of model; 0 , at $0.75 \mathrm{~L}$ of model; $\longrightarrow$, regression line; L, enclosure length; $u_{\max }$, maximum velocity of the air-jet at specific distance from the inlet wall

the viscosity term should not be neglected for low Reynolds number flow because of the expansion of the air-jet is caused by the insignificant airspeed and viscous effects in this region. Thus the possible similitude criterion might be $R e$ at low Reynolds number flow (laminar inlet flow), and $R_{m}$ which related to $u_{d}$ at high Reynolds number flow (turbulent inlet flow) of a particular range. The implementation of using $R_{m}$ (or $u_{d}$ ) as the similitude criterion in a slot-ventilated enclosure under isothermal condition is in agreement with the results of Adre and Albright (1994).

Using $R_{m}$ as the similitude criterion results in the design condition of scaling law between the model and 
Table 2

Regression equations of peak velocity of the air-jet $u_{\max }$ at specific distance from inlet wall in the model and prototype against Reynolds number $R e$, jet momentum ratio $R_{m}$, and air-jet velocity at diffuser $u_{d}$

\begin{tabular}{|c|c|c|c|c|}
\hline Parameters & Position ( $x$ ) & Chamber type & Equations & $R^{2}$ \\
\hline $\operatorname{Re}$ & $\begin{array}{l}0.25 L \\
0.5 L \\
0.75 L\end{array}$ & $\begin{array}{c}\text { Model } \\
\text { Prototype } \\
\text { Model } \\
\text { Prototype } \\
\text { Model } \\
\text { Prototype }\end{array}$ & $\begin{array}{l}u_{\text {max }}=0 \cdot 0011 R e \\
u_{\text {max }}=0 \cdot 0006 R e \\
u_{\text {max }}=0 \cdot 0009 R e \\
u_{\text {max }}=0 \cdot 0004 R e \\
u_{\text {max }}=0 \cdot 0007 R e \\
u_{\text {max }}=0.0003 R e\end{array}$ & $\begin{array}{l}0.9966 \\
0.9873 \\
0.9963 \\
0.9909 \\
0.9944 \\
0.9785\end{array}$ \\
\hline$R_{m}$ & $\begin{array}{l}0 \cdot 25 L \\
0 \cdot 5 L \\
0 \cdot 75 L\end{array}$ & $\begin{array}{l}\text { Model and prototype } \\
\text { Model and prototype } \\
\text { Model and prototype }\end{array}$ & $\begin{array}{l}u_{\max }=9.4444 R_{m}^{0.5145} \\
u_{\max }=7 \cdot 5004 R_{m}^{0.5217} \\
u_{\max }=6 \cdot 3206 R_{m}^{0.5525}\end{array}$ & $\begin{array}{l}0.9914 \\
0.9945 \\
0.9845\end{array}$ \\
\hline$u_{d}$ & $\begin{array}{l}0 \cdot 25 L \\
0 \cdot 5 L \\
0 \cdot 75 L\end{array}$ & $\begin{array}{l}\text { Model and prototype } \\
\text { Model and prototype } \\
\text { Model and prototype }\end{array}$ & $\begin{array}{c}u_{\max }=0.739 u_{d} \\
u_{\max }=0.5782 u_{d} \\
u_{\max }=0.4542 u_{d}\end{array}$ & $\begin{array}{l}0.993 \\
0.9963 \\
0.9936\end{array}$ \\
\hline
\end{tabular}

$x$, Horizontal distance from the inlet wall; $L$, enclosure length; $R^{2}$, coefficient of determination.

prototype (denoted by subscripts $m$ and $p$ ) as

$$
\left(\frac{h u_{d}^{2}}{L+H}\right)_{m}=\left(\frac{h u_{d}^{2}}{L+H}\right)_{p}
$$

where $H$ is the enclosure height in $\mathrm{m}$.

$$
\operatorname{As}\left(\frac{h}{L+H}\right)_{m}=\left(\frac{h}{L+H}\right)_{p},
$$

then:

$$
\left(u_{d}^{2}\right)_{m}=\left(u_{d}^{2}\right)_{p}
$$

or

$$
u_{d, m}=u_{d, p}
$$

Using $E u$ as the similitude criterion will result in the same design condition as using $R_{m}$ when the pressure difference is identical in both the model and prototype:

$$
\left(\frac{2 \Delta \mathrm{P}}{\rho u_{d}^{2}}\right)_{m}=\left(\frac{2 \Delta \mathrm{P}}{\rho u_{d}^{2}}\right)_{p}
$$

where: $\Delta P$ is the pressure difference in $\mathrm{N} / \mathrm{m}^{2}$; and $\rho$ is the density of air-jet in $\mathrm{kg} / \mathrm{m}^{3}$. If the same working fluid and the same pressure difference were implemented, then,

$$
\left(u_{d}^{2}\right)_{m}=\left(u_{d}^{2}\right)_{p}
$$

or

$$
u_{d, m}=u_{d, p}
$$

The plot of Fig. 5(c) shows that values of Eu concentrate at 0.11 and 0.88 in the model and prototype, respectively. The parameter $\Delta P$ equals the pressure difference between the inlet and outlet of the enclosure in the analysis. The results of experiments indicate that $\Delta P$ is proportional to the inertia force of the air-jet as $\rho u_{d}^{2} / 2$, and the values of $E u$ in a specific model approach to a constant value even the inertia force of the air-jet varied. As the loss of total energy of the air-jet varies in different geometry model, the value of $E u$ concentrates to different value in dissimilar scale models. The results of experiments are opposed to the conclusion that the similar airflow is defined with the same $E u$ by Rousseau and Albright (1996).

Jin and Ogilvie (1990) derived the change of airflow patterns in an enclosure under isothermal conditions as four stages (Fig. 6). In stage 1, the incoming jet velocity is very low and cannot reach the sidewall [Fig. 6(a)]. The mean air velocity at the floor region is less than $0.1 \mathrm{~m} / \mathrm{s}$. As the inlet velocity increases, the air-jet reaches the sidewall and flows along the wall towards the floor as stage 2 [Fig. $6(b)]$. The mean air velocity at the floor region is greater than $0.1 \mathrm{~m} / \mathrm{s}$. If the inlet velocity continues to increase, the air-jet reaches the floor and travels along the floor as stage 3 [Fig. 6(c)]. Further increase of inlet air velocity will result in the fully rotary flow as stage 4 [Fig. $6(d)]$. Any further increase of the inlet air-jet velocity will not change the airflow pattern inside the enclosure but increase the velocity of the rotary airflow. Distinguish of the airflow pattern inside an enclosure under isothermal condition depends on the length of the trajectory that the air-jet can travel along.

A plane wall Jet is diffused from a slot-inlet and is terminated when the peak velocity of the air-jet is $0.5 \mathrm{~m} / \mathrm{s}$ (ASHRAE, 1993). The distance from the diffuser to a point where the peak velocity in the cross stream section of the air-jet reduced to the terminal velocity is the jet throw. The jet throw also represents the air-jet trajectory which creates the airflow pattern inside the enclosure. The jet throw $L_{j}$ in $\mathrm{m}$ can be derived from Eqn (1) 


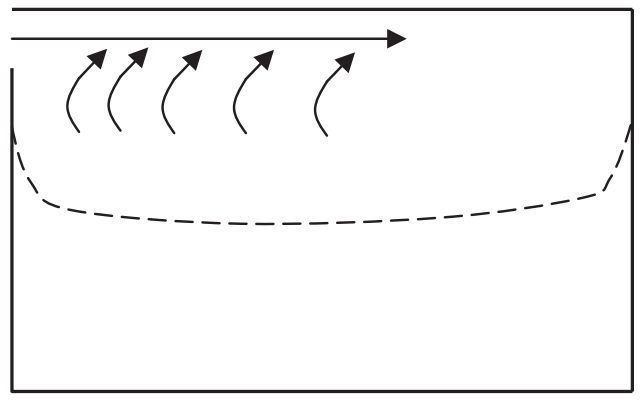

(a)

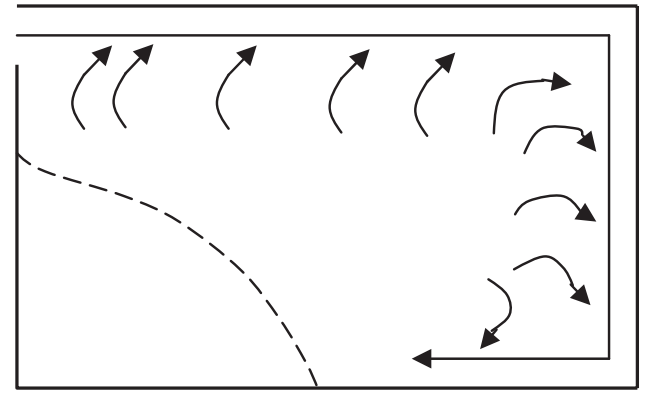

(c)

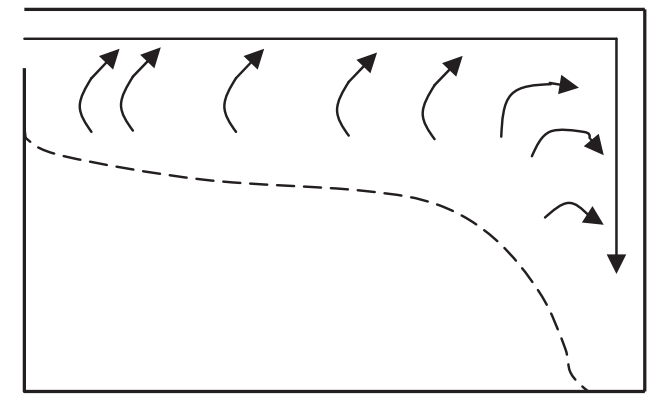

(b)

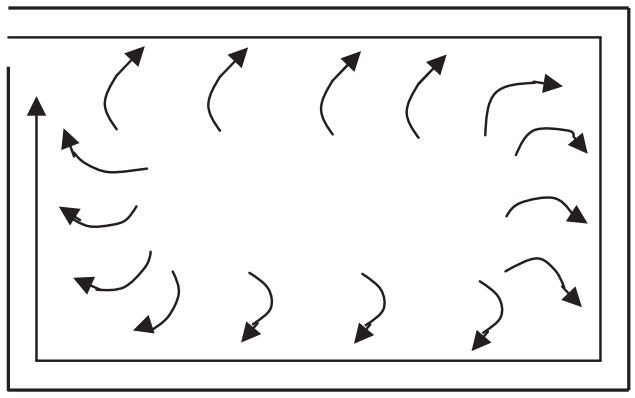

(d)

Fig. 6. Four-stage airflow patterns visualised in a prototype slot-ventilated enclosure; (a) stage 1, the incoming jet velocity is very low and cannot reach the sidewall; (b) stage 2, the air-jet reaches the sidewall and flows along the wall towards the floor; (c) stage 3 , the air-jet reaches the floor and travels along the floor; (d) stage 4, the inlet air velocity will result in the fully rotary flow

in both the ceiling region and the floor region because the wall-jet at the floor region behaves like a plane wall jet after the reverse air-jet has impinged on the floor (Jin \& Ogilvie, 1990; Yu et al., 2003):

$$
L_{j}=\left(\frac{C_{w} u_{d}}{u_{t}}\right)^{2} h
$$

where $u_{t}$ is the terminal velocity of the air-jet in $\mathrm{m} / \mathrm{s}$.

If similar airflow patterns between the model and prototype are proposed, then the normalised jet throws $L_{j} / h$ will also be the same as

$$
\left(\frac{L_{j}}{h}\right)_{m}=\left(\frac{L_{j}}{h}\right)_{p}
$$

Substituting Eqn (9) to Eqn (10) gives

$$
\left(\frac{C_{w} u_{d}}{u_{t}}\right)_{m}^{2}=\left(\frac{C_{w} u_{d}}{u_{t}}\right)_{p}^{2}
$$

and because $C_{w, m}=C_{w, p}$, then:

$$
\left(\frac{u_{d}}{u_{t}}\right)_{m}^{2}=\left(\frac{u_{d}}{u_{t}}\right)_{p}^{2}
$$

or

$$
\left(\frac{u_{d}}{u_{t}}\right)_{m}=\left(\frac{u_{d}}{u_{t}}\right)_{p}
$$

As the terminal velocity $u_{t}$ of a plane wall jet in both the model and prototype is $0.5 \mathrm{~m} / \mathrm{s}$, thus

$$
u_{d, m}=u_{d, p}
$$

The similar inlet airspeed in both the model and prototype will result in the same jet throw which creates similar airflow pattern inside the enclosure.

Complete similitude of the airflow field between the scale-model and prototype requires geometric similitude, kinematic similitude, dynamic similitude, and all boundary conditions in isothermal conditions. Geometric similarity requires that the model and prototype have the same shape, and all the linear dimensions of the model are related to the corresponding dimensions of the prototype by a constant scale factor (Fox et al., 2004). Kinematic similarity exists between the model and prototype when the streamline pattern is the same and corresponding velocity ratios between velocity of the model $u_{m}$ and of the prototype $u_{p}\left(u_{m} / u_{p}\right)$ and acceleration ratios between acceleration of the model $a_{m}$ and of the prototype $a_{p}\left(a_{m} / a_{p}\right)$ are constant throughout the flow field, where $a_{m}, a_{p}$ are the air-jet acceleration for the model and prototype, respectively, in $\mathrm{m} / \mathrm{s}^{2}$. If the ratio of forces in the model and prototype to be the same, we have dynamic similarity between the model and prototype (Young et al., 2004). 
From the setting of experiments, geometric similarity is validated by proposing the same shape and scaling the linear dimensions by a constant ratio between the model and prototype. The similar peak velocities of the air-jet at comparative positions will result in the corresponding velocity ratio between the model and prototype. Thus the kinematic similarity in the model and prototype is achieved. The airflow pattern of a two-dimensional wall jet inside an enclosure is the result of integrated effects between relevant forces acted on the air-jet. The similar jet throw of the plane wall jet causes analogous airflow pattern in an enclosure. The same inlet airspeed of a plane wall jet in both the model and prototype will result in the corresponding jet throw which cause similar airflow pattern and gives dynamic similarity in the model and prototype.

\section{Conclusions}

From above discussion, Reynolds number Re may be validated as similitude criterion only at low Reynolds number flow, and the threshold value to discriminate the boundary of laminar flow still needs to be studied. Euler number $E u$ may not be the similitude criterion for a twodimensional wall jet in mechanically ventilated spaces under isothermal condition based on the experimental results. On the other hand, the jet momentum ration $R_{m}$, which related to the inlet velocity $u_{d}$, indicates consistent peak velocity in comparable distance between different models is the similitude criterion for a two-dimensional wall jet in mechanically ventilated spaces under isothermal condition. The dilemma of using the dimensional parameter as similitude criterion is based on the physical performance of the plane wall jet inside an enclosure. The air-jet will vanish when the peak velocity of the air-jet decreases to the terminal velocity which is a constant value in both the model and prototype. It requires that the inlet air-jet velocity also is identical in both the model and prototype to get the similar air-jet throw and airflow pattern by self-similarity of the air-jet velocity.

These results provide evidence that the similar airflow in geometrically alike mechanically ventilated confined spaces under isothermal condition can be achieved by using $R_{m}$ (or $u_{d}$ ) as similitude criterion, and are in agreement with the results presented in the literature.

\section{Acknowledgements}

This study is officially supported by the funding from National Science Council of the Republic of China under the grant NSC-89-2313-B-197-016.

\section{References}

Adre N; Albright L D (1992). Criterion for establishing similar airflow patterns in slotted-inlet ventilated enclosure. ASAE Paper No. 92-4530, St Joseph, MI

Adre N; Albright L D (1994). Criterion for establishing similar airflow patterns (isothermal) in slotted-inlet ventilated enclosures. Transactions of the ASAE, 37(1), 235-250

Albright L D (1976). Airflow through hinged baffle slotted inlets. Transactions of the ASAE, 19(4), 728-735

ASHRAE (1993). ASHRAE Handbook: Fundamentals. American Society of Heating, Refrigeration and AirConditioning Engineers, Atlanta, GA

Awbi H B (1991). Ventilation of buildings. Chapman \& Hall, London

Barber E M; Sokhansanj S; Lampman W P (1982). Stability of airflow patterns in ventilated airspaces. ASAE Paper No. 82-4551, St Joseph, MI

Baturin V V (1972). Fundamentals of Industrial Ventilation, 3rd Edn. Pergamon Press, Oxford, UK

Forthmann E (1934). Turbulent jet expansion. National Advisory Committee for Aeronautics, Technical Memorandum No.789

Fox R W; McDonald A T; Pritchard P J (2004). Introduction to Fluid Mechanics, 6th Edn. John Wiley \& Sons, Inc., New York, NY

Jin Y; Ogilvie J R (1990). Near floor air speeds from center slot air inlets in swine barns. ASAE Paper No. 90-4004, St Joseph, MI

Jin Y; Ogilvie J R (1992). Airflow characteristics in the floor region of a slot ventilated room (isothermal). Transactions of the ASAE, 35(2), 695-702

Liu Q; Hoff S J; Bundy D S (1995). A comparison of three proposed ventilation criteria. ASAE Paper No. 95-4642, St Joseph, MI

Moog W (1981). Room flow tests in a reduced-scale. ASHRAE Transactions, 87(4), 1162-1181

Murphy G (1950). Similitude in Engineering. Ronald Press Co., New York, NY

Pattie D R; Milne W R (1966). Ventilation airflow patterns by use of models. Transactions of the ASAE, 9(5), 646-649

Rousseau A N; Albright L D (1996). An alternative kinematic similitude criterion for slot-ventilated enclosures. Transactions of the ASAE, 38(6), 1887-1889

Schlichting H (1979). Boundary-Layer Theory. McGraw-Hill, Inc., New York, NY

Shepherd D G (1965). Elements of Fluid Mechanics. Brace \& World, Harcourt, NY

Smith M R; Hazen T E (1968). Similitude study of ventilationinlet configuration. Transactions of the ASAE, 11(2), $218-225,235$

Szucs E (1980). Similitude and Modeling. Elsevier Scientific Publishing Co., Amsterdam, Netherlands

Thorshauge J (1982). Air-velocity fluctuations in the occupied zone of ventilated spaces. ASHRAE Transactions, 88(2), 753-764

Timmons M B (1984). Use of physical models to predict the fluid motion in slot-ventilated livestock structures. Transactions of the ASAE, 27(2), 502-507

Timmons M B; Baughman G (1981). Similitude analysis of ventilation by stack effect from an open ridge livestock structure. Transactions of the ASAE, 14, 1030-1034 
Yao W Z; Christianson L L; Muehling A J (1986). Air movement in neutral pressure swine buildings-similitude theory and test results. ASAE Paper No. 86-4532, St Joseph, MI

Young D F; Munson B R; Okiishi T H (2004). A Brief Introduction to Fluid Mechanics, 3rd Edn. John Wiley \& Sons, Inc., New York, NY

Yu H (1996). Air mixing criteria foe ceiling slot-ventilated agricultural enclosures. Unpublished PhD Dissertation, Iowa State University, Ames, IA

Yu H; Hoff S J (1994). Validation of the momentum ratio concept for isothermal airflow similarity in a ceiling slotventilated enclosure. ASAE Paper No. 94-4582, St Joseph, MI

Yu H; Hoff S J (1999). Airflow pattern similitude criteria for ceiling slot-ventilated agricultural enclosures under isothermal conditions. Transactions of the ASAE, 42(2), 459-469

Yu H; Liao C M; Liang H M (2003). Scale model study of airflow performance in a ceiling slot-ventilated enclosure: isothermal condition. Building and Environment, 38, $1271-1279$

Zhang J S (1991). A fundamental study of two-dimensional room ventilation flows under isothermal and non-isothermal conditions. Unpublished PhD Dissertation, University of Illinois at Urbana-Champaign, Urbana, IL

Zhang J S; Christianson L L; Riskowski G L (1991). Effect of diffuser air velocity profiles on scaling methods for predicting room air motion. ASAE Paper No. 91-4558m St Joseph, MI 